\title{
The trauma-self and its resistances in psychotherapy
}

\begin{abstract}
This paper seeks to highlight phenomena related to resistance in the psychotherapy of dissociative disorders and other trauma- and stress-related psychiatric disorders. The authors consider a particular psychological construct to be at the origin of resistance: the trauma-self. The resistances of the trauma-self consist of three main groups: Depressive manifestations, traumatic obsessions, and loss of psychosocial mutuality. Detemporalization, treating oneself as an object, suicidality, obsessions of abnormality, rupturing the mutuality of the patient-therapist relationship, and dissociative somatic crises are clues of these resistances. Succesful treatment is expected to minimize the resistances of the trauma-self. This is expected to be achieved through the careful contextualization of the trauma-self while conducting psychotherapy. Approaching the patient's experiences from multiple angles not only from the angle of the therapist but also from the patient's distinct perspectives are crucial in working through the resistances of the trauma-self.
\end{abstract}

Volume 6 Issue 6 - 2016

\author{
Erdinc Ozturk,' Vedat Sar ${ }^{2}$ \\ 'Department of Social Sciences, Institute of Forensic Medicine, \\ Istanbul University, Istanbul, Turkey \\ ${ }^{2}$ Department of Psychiatry, Koc University School of Medicine \\ (KUSOM), Istanbul, Turkey
}

Correspondence: Vedat Sar, Department of Psychiatry, Koc University School of Medicine KUSOM, Rumelifeneri Yolu, Sariyer 34450 Istanbul Turkey, Email vsar@ku.edu.tr

Received: October 31, 2016 | Published: December 07, 2016

Keywords: psychotherapy, trauma, dissociation, resistance, trauma-self

\section{Introduction}

Freud $^{1}$ introduced the idea of resistance in his early work on hysteria today's chronic complex dissociative disorder to describe a phenomenon he had observed during the treatment of a 24-year-old patient, Fraeulein Elisabeth von R., namely, her inability to remember and her failure to cooperate. He proposed that the resistance in his dissociative client was the same psychic force that had created the symptom in the first place. ${ }^{2}$ His concept of resistance evolved after these first accounts, so that he stated later simply: "whatever disturbs the progress of the work is a resistance". ${ }^{3}$ According to Bromberg, ${ }^{4}$ representing an "illogical" wish to stay the same while changing p.170, resistance is a hindrance in treatment process which requires to be worked on. It is considered to be a universal phenomenon in psychotherapy today; all clients, despite their suffering, want to preserve the status quo. ${ }^{5}$ As a concept, resistance is defined today rather as the patients' resistance to knowing what is in their own mind; i.e. a clinical phenomenon encompassing all of a patient's defensive efforts to avoid self-knowledge. ${ }^{6}$

Although positive outcomes have been reported ${ }^{7,8}$ and consensus on standards of treatment has been established, ${ }^{9}$ psychotherapy of chronic complex dissociative disorders continue to be beset by many challenges. ${ }^{10}$ Based on our clinical experience with hundreds of trauma-related chronic complex dissociative patients throughout more than two decades of clinical work, we consider resistance still to be an important concept in the psychotherapy of trauma-related conditions. Thus, we have focused our inquiries on the origin of the treatment barrier which seems to place the patient out of contact impossible to reach. Repetitive crisis situations have been inevitable without appropriate technical interventions to overcome the barrier. In fact, it was treatment-resistant and crisis-prone patients who helped Sar and Ozturk ${ }^{11}$ clarify their own model in understanding traumarelated dissociation. We consider a particular psychological construct to be at the origin of resistance in the psychotherapy of trauma-related conditions: the trauma-self. We propose that effective psychotherapy of these patients must be informed about the trauma-self and its resistances. In our observation, in the beginning of the treatment of dissociative patients, the psychotherapist is usually in contact with the trauma-self. However, being unaware of and not addressing resistances of the trauma-self may leave the therapeutic work quite unproductive. The trauma-self becomes the psychological centrum of the patient but the problem-solving abilities are then locked throughout treatment. Thus, the aim of this paper is to make therapists aware of this potential hindrance in treatment of trauma-related dissociative disorders and provide an intellectual tool to prevent them from a circulus vitiosus in their clinical work.

\section{What is the trauma-self?}

The concept of self has multiple meanings in psychiatry, psychoanalysis, anthropology, psychology, neurology, philosophy, sociology, and cultural studies. There is a general consensus that a self can be understood through five aspects: agency, an identity, a life trajectory,a history, and a perspective. Many authors insist that identity consists of multiple selves, including trauma-related ones. ${ }^{4,12}$ On the other hand, Sadler ${ }^{13}$ considers mental disorders separate from personal self. The notion of a front-line-self hiding the authentic characteristics of a person has also been maintained in sociology, psychology, and psychoanalysis. ${ }^{14}$ Recently, Metzinger ${ }^{15}$ states that no such things as selves exist. He proposes that all that exists are contents of transparent self-models phenomenal selves as ongoing processes which appear in conscious experience. Although our approach has links to all these notions, given the extreme diversity of the standpoints, an inquiry about the essence of the self extends the limits of this study. Thus, the concept of trauma-self is used in this paper as a heuristic device to aid in understanding a clinical phenomenon which is thought to have strategic importance in the treatment of complex dissociative disorders, and in fact, in all trauma-related disorders with a particular emphasis on developmental complex trauma.

We assume that the origin of the trauma-self is the inadequate processing of trauma. Thus, the trauma-self emerges through transformation of the pre-trauma-self following the "traumatic turning point" as described by Sar and Ozturk. ${ }^{16}$ Social contacts are established then through the trauma-self. ${ }^{17}$ The effects of the traumaself on psychosocial mutuality may lead to clinical phenomena such as being vulnerable and open to external influences, ${ }^{18}$ impairment of self-regulation, ${ }^{19}$ problems of distance and temperance in social contacts ranging from detachment to fusionary relationships, ${ }^{20}$ and polarized responses ranging from lack of response to over-reactivity ${ }^{21}$. Hence, in fact, trauma-self functions like a symptomatic self while the symptoms originate from its resistances. Until awareness is developed during psychotherapy, the subject can not realize that he/she makes 
social contacts using the trauma-self. The emerging trauma-self increasingly becomes a hindrance against processing the trauma. The healthy human self is innately open to development, progression, and growth. On the contrary, the rather rigid trauma-self is the source of psychopathology and clinical symptoms. In other words, the traumaself is one which resists to treatment. Increasing the awareness about the trauma-self is itself helpful in minimization of its resistances.

Given the extensive utilization of a number of similar concepts in trauma-related psychopathology, one may ask what the unique aspect of the trauma-self is. We consider the trauma-self as an enduring psychological construct which is more elaborated than a distinct alter personality state. The trauma-self is different from an "emotional part of personality". ${ }^{22}$ because the "remaining part" is considered as problem-solving one rather than an emotionally restricted "apparently normal part of personality". Although the trauma-self may have transient ties to emotions, it is not an origin of emotions. Speaking with Janet's terms, the trauma-self is not characterized by a lack of "personification" either. ${ }^{22}$ On the contrary, the presence of the traumaself indicates that the person continues to claim to own the traumatic experience while trying to process it, (albeit unsuccesfully). Although each distinct personality state disappears following a "fusion" in dissociative disorders, a similar intervention is not available for the trauma-self; the trauma- self may prevail even after integration of all distinct personality states. In fact, the trauma- self does never dissolve; it may be reactivated by subsequent traumatic experiences of the magnitude sufficient to initiate new traumatic turning points. Having had an effective previous treatment may be helpful to cope with the resistances emerging during subsequent reactivations. Distinct personality states, however, can not be reactivated after successful treatment.

\section{The resistances of the trauma-self}

We cluster the resistances of the trauma-self into three groups: Depressive manifestations also called "dissociative depression", $23-25$ traumatic obsessions, and loss of psychosocial mutuality. Being a result of inadequate trauma processing, they tend to appear together. Any of them may be seen in other psychiatric conditions also, however, they constitute a bundle of interrelated phenomena when observed in dissociative disorders. ${ }^{26}$ Thus, succesful therapeutic work on the trauma-self would help in overcoming of these phenomena all together and, consequently, in improving the clinical condition.

\section{Depressive manifestations}

Uprising against present time: Being stuck in the past and obstructed by a dysimaginated future, the traumatized subject is unable to experience time in the present. ${ }^{27}$ Consequently, she wishes or believes to be non-existent. The traumatized subject cannot experience time (i.e. normal time perception turns to traumatic time perception). The unprocessed trauma is repeatedly mulled over. These repetitions aimed at finding resolution become traumatic obsessions. ${ }^{16}$ Traumatic obsessions double the perception of the present. Feelings of non-existence and traumatic obsessions cause anger. Traumatic time perception and traumatic obsessions turn normal memory to traumatic memory. Due to impaired linking capacities, the mind remains focused on the lost memory.

The myth of being unchangeble: The subject is convinced that negative experiences are permanent and there is no chance for any positive possibility in his life. He believes that nothing can change and he also will remain the same.
The need to be neutral: Being neutral is better than being depressed. Hopes and wishes have to be reduced. Even when a wish arises although rarely nothing can be done to bring it to pass. Being unable to feel anything, all thoughts, emotions, and behavior are frozen or stuck. This is a devalued, uncommitted stance where nothing is certain and ambiguity prevail.This stance may lead the subject to enter into a stupor.

Treating oneself as an object: In similar fashion to how others have dealt with him, the subject converts himself into an object. In this way, he wants to convince himself of being in control. However, as he cannot feel, he can cut himself like a piece of paper or he can throw himself from the balcony like an object rather than a human. This is a dissociative engine first noticed by Freud ${ }^{28}$ in "Mourning and Melancholia".

Psychological "arrest": Major depression, death and ideas of suicide become prominent. Preoccupation with a death wish is related to the wish to capture the time. One believes that perception of the present is possible only while experiencing death. The loneliness experienced while exposed to the traumatic event is a prototype of this situation, because it distorts and refutes the hopes of what one imagines and wishes to become as a person (dysimagination). After realizing the unavailability of the imagined characteristics, one moves from life to death themes. All positive investments for oneself are relinquished. A link to life is no longer perceived. Suicidal thinking is a necessary resistance to tolerate the intensity of psychotherapy by guaranteeing an "escape hatch" from "hell", i.e. life.

\section{Traumatic Obsessions}

The desire to start over from the beginning: This is an urge to delete everything in life and to start over again. If only everything had not happened, if only one could forget everything one experienced, or if only one could continue life as somebody else. Sometimes the person uses all his concentration on these ideas and tries to stay at a distance from his environment, himself, and the events he experienced.

Self-pity: Personal boundaries have been violated and no place remains for a minimum of autonomous activity. Self-pity builds distance from other people. All of one's energy is devoted to remaining at a distance from people.

Phobia against pity: Self-pity gradually transforms into a phobia against pity. The prominent idea then is: "Do not pity yourself, hate yourself instead, because a hated person does not inspire pity". Consequently, self-pity disappears, but self-hate replaces it.

Obsessions with abnormality: Being traumatized, life is considered to be abnormal. Moreover, one believes that nothing is going to be normal. This obsession interferes with having normal responses in normal social life. However, the person is not aware of the loss of temperance in his/her responses and in his/her distancing during communications.

Fear of "going crazy": One worries that one is going to be "crazy". When becoming "crazy", one believes that one will be able to escape from invasion of the trauma. One believes that one can not bear one's experiences without becoming "crazy". This is such a pressing feeling that one can not wait and thinks that this "ultimate crisis" should happen immediately.

Phobia against normality: The non-pathological life is perceived as ordinary and boring which is unbearable. Risk-taking behavior and an unstable life are considered more acceptable then. The subject believes she is not able to maintain a normal life. 


\section{Loss of psychosocial mutuality}

Narcissism: The traumatized person is self-absorbed and relatively oblivious to others.

There is a close relationship between narcissism, abuse, and dissociation. ${ }^{4,17}$ Early and chronic trauma may lead to pathological narcissism. ${ }^{20}$ As an extention of this link, narcissism has been proposed to be the interpersonal aspect of dissociation. ${ }^{17}$ Dissociative subjects create an internal world of attachment objects which serve as a buffer for further traumatization. However, this non-interactive solution leads them to a detachment from external world; i.e. to interpersonal dissociation and to further loss of mutuality between internal world and external reality. There are also traumatized subjects without narcissistic features and this is not rare. These traumatized subjects appear non-responsive, suggestible, anger-prone, numb, depressed and unstable. Although both groups may have dissociative experiences, the narcissistic ones appear more integrated/whole and stable than non-narcissistic ones. With this capacity, they may become a perpetrator despite their own traumatic background.

Oscillation in relationships: During the process of trauma, mutuality is lost in almost all relationships. ${ }^{29,30}$ Because, one has been left alone and has not received adequate support. One gradually becomes aware of pseudomutualities in communications and starts to keep people at a distance.

Dissociative somatic (conversion, functional neurological) symptoms: Acute dissociative somatic symptoms usually happen during an internal control struggle and due to a striving to be accepted by a rejecting interpersonal environment. It usually follows a period of overadjustment. Most of the subjects with a chronic dissociative disorder develop transient conversion symptoms. ${ }^{31,32}$ Depersonalization is a common accompaniment of circumscribed conversion symptoms among these patients ${ }^{33}$ while it is less prominent in subjects with multiple somatic complaints as observed in somatization disorder. ${ }^{34}$ Multiple somatic complaints may hide a complex trauma history. ${ }^{35}$

Dissociative psychosis: Known also as hysterical psychosis ${ }^{36}$ for many decades and being, in fact, a pseudopsychosis, it is qualitatively distinct from schizophrenia and any other 'endogenous' psychosis. ${ }^{37}$ A transient dissociative psychosis episode may be superimposed on a chronic dissociative disorder (e.g. DID) as a complication. ${ }^{38}$ The trauma-self is not in charge in this condition. The seeming nonexistence of the trauma- self is the resistance here. This is the peak experience and the final stage of the fear of going 'crazy'.

\section{The trauma-self in psychotherapy dissociative identity disorder}

The trauma-self is a front-line construct which hides further psychopathological contents and hinders the entrance to it. The resistances of the trauma-self may mislead the therapist, make core problems invisible, prevents the patient from actively participating in the therapeutic work, and may even lead to misdiagnosis or pseudocomorbidities. Thus, in order to continue with the treatment, these resistances should be minimized. The concept of "angle of view" is the key element in our approach to minimize the resistances of the trauma-self. ${ }^{31,39}$ In dissociative identity disorder DID, several but not all distinct personality states may contain trauma- self's angle of view permanently or transiently. The "host" personality compels some of the "alter" personalities to adopt the trauma-self's angle of view. Consequently, the person looks at himself from the perspective of the trauma- self. In such a condition, the patient continuously depicts himself/herself in a situation of helplessness. This is a hindrance for progression of treatment. Thus, as a basic principle of treatment, we propose that the psychotherapy of unresolved trauma involves looking oneself repeatedly in the context of different versions of reality (see also Bromberg, 1999). The person should try to perceive himself in each of these contexts, and to make sociopsychological links between these "realities" and between related perceptions of self. We have four basic assumptions concerning the "angles of view" of "host" and "alter" personalities and of the therapist toward each other: 1) The attitudes of the host personality and alter personalities toward the therapist differ, 2) The host personality identifies alter personalities in a distorted fashion, 3) The therapist usually considers the relationship between the host and alter personalities to be a causal one "therapist view", 4) Alter personalities consider the host personality to be an "idiot". The angle of view should be considered when talking to the alter and the host personalities. It determines the context of the therapeutic conversation. Most of the therapists have in mind how to change the (persecutory) alter personalities' attitudes; i.e. how to turn a persecutory alter personality to a helper one. However, this approach is adopted from the host personality's angle of view. The more strategic approach is to change the host's prejudice against an alter personality. To achieve this, the function of any alter personality and the way it is perceived by the host personality should be dissected from each other.

\section{Case example:}

A 21-year-old male university student with DID had a twoyear previous psychiatric treatment without any improvement. He constantly had suicidal ideas and had made multiple suicide attempts using chemical drugs. He maintained food refusal for months; had dissociative amnesias, had alter personality activities, and engaged in alcohol and marihuana use. He was molested sexually during two separate incidents when he was 9 and 10 years old including anal penetration. He had rage feelings against the perpetrators tradesmen in his neighborhood and fantasized killing them. He had also suffered from chronic neglect, and physical and emotional abuse by his parents and had experienced emotional abuse by his peers in childhood.

He was experiencing helplessness and hopelessness and said to his new therapist E.Ö in the first interview: "I will commit suicide. You look like a good person; I recommend you that you not take on my treatment and save yourself the trouble". However, he accepted a contract not to attempt suicide when the therapist promised a successful treatment in a maximum duration of two years. He reported fears of "going crazy" and self-pity. Occasionally, he felt to be an "important" person to be able to "change the world". He was full of wish to start the life over from the beginning and to erase "everything" what he had in his mind.

The patient remained depressed throughout whole treatment period. Anxiety, loss of weight, sleep disturbances, suicidality did not respond to any intervention including diverse antidepressant medications and a series of electroconvulsive treatment. It was not possible to contact any alter personality in the course of one year. It finally occurred spontaneously when an overt switching took place during a session. He reported that there were more than 20 alter personalities. Almost all of them were of a persecutory type and they insisted that the patient should be killed, because he was once not able to protect himself.

The alter personalities were fantasizing to kill the perpetrators of childhood traumas. In fact, it was originally the wish of the host 
personality relegated as the mission of the alter personality. The alter personality was perceiving this as an assistance to the host personality. This "angle of view" was the one which was attributed to the alter personalities by the host personality. The therapist asked the patient if there was an other way to help him. All dynamics of alter personalities were organized according to the host's angle of view. The host personality believed that the alter personalities were pursuing revenge and wanted to kill him. The alter personalities had owned the host's angle of view as their function. In fact, they originally had different usually helping functions. The alter personalities came to realize that their persecutory attitudes were shaped by the host personality's angle of view.

The appropriate question when an alter personality is met for the first time is: Who is the alter personality? The activities of the alter personality are less important than its identity. The therapist should never enter into a competitive relationship with alter personalities. The key attitude is a sort of neutrality similar to that of a public interviewer rather than a therapist (a "matter of fact" attitude). ${ }^{40}$ The relationship and the dialogues between the therapist and the alter personalities should be witnessed by the host personality. This process would help the host personality to overcome his prejudices about alter personalities. Alter personalities that are not part of this process become an origin of resistance in psychotherapy ("alter personality resistance"). The prejudices of the host personality also interfere with psychotherapy and the host personality itself may also turn to be an origin of resistance to treatment ("host personality resistance"). Giving to the host personality the opportunity to observe the alter personalities in a relationship with the therapist prevents or solves both types of resistance.

\section{Case example:}

A 22-year old male DID patient with a five-year history of unsuccesful psychotherapy had lost his hope for healing and was full of wishes for death. When his treatment was taken over by a new therapist E.Ö, he had depressive complaints, could not sleep well, had anger outbursts with temper tantrums and intermittant self-mutilative behavior. He had transient conversion symptoms and "could not experience the present time" occasionally. He was dissatisfied with his previous treatment, he talked about how much he paid for these useless efforts. He complained about his life, family, and job. He was believing that his condition would never improve.

He had four alter personalities. The intervention was focused on making him aware of his trauma-self. The therapist pointed out to him his complaining and dissatisfied attitude. The patient acknowledged he had been conducting himself in this style for many years. The therapist proposed to the patient that he was detached from his problem-solving abilities and asked the patient whether he still kept them. The patient admitted that he had problem-solving abilities he no longer uses. His involvement with his trauma-self led him to dissociate from his problem-solving abilities.

The therapist dealt with the alter personalities after this intervention. The host personality's imaginations about alter personalities were distorted; i.e. he was prejudiced against them. The patient complained about alter personalities whenever he was under the control of the host personality. He insisted that alter personalites were frightening him and his life would be better without them. In fact, one of the alter personalities the host personality believed that this one was frightening and torturing him had problem-solving abilities. The patient realized this when the therapist contacted this alter personality directly.
The host personality was instructed to listen to the dialogue between the therapist and the alter personality. The alter personality's problem-solving actions experienced in previous events were included in the dialogue. The prejudiced and distorted view of the host personality toward the alter personality was uncovered. The patient was integrated in five interviews and the overall improvement was obvious to him, to his family, and to the therapist. All depressive manifestations and complaining behavior disappeared.

The trauma-selfis usually displeased, complaining, depressed, and lamenting. The main tool of the therapist is an active and mobilizing approach. This is helpful in adressing passive-agressive behavior in particular. ${ }^{41}$ One may intervene by means of clarifications, confrontations, and interpretations. The therapist also mobilizes problem-solving abilities in terms of a rather fighting attitude. Most therapists agree that a kind of trauma work is inevitable for treatment of dissociative disorders and other trauma-related conditions..$^{42}$ The accent has shifted from abreaction to a more integrative workingthrough in a phase-oriented fashion throughout the last decades. ${ }^{9,30,43}$ In our view, abreaction per se does not have any therapeutic value. It may be useful to treatment only, if appropriate interventions are conducted, i.e. being aware of the traumatic self and its resistances and working on them. If the patient cannot accurately process a new traumatic experience, the traumatic self will then become reactivated.

\section{Case example:}

A 26-year old female patient with DID reported anxiety and death wishes. She felt hopeless about her treatment. Although she had been in psychotherapy for five years, she was in partial social withdrawal. She was contacting young men in person whom she entered into dialogue through internet chatting. She was hospitalized once for an eating disorder yet she still had a distorted body image i.e. she believed whe was fat despite her quite thin body shape. She was molested sexually by her grandfather throughout her childhood. Her condition deteriorated after the death of her father two years ago. She had fears of "going crazy" and experienced conversion symptoms transiently. Her previous therapists listened to the complaints and lamenting of the patient for five years and fusions between alter personalities had been conducted whenever possible.

She still had seven alter personalities when she started treatment with her new therapist E.Ö. Complaints, crying spells and lamenting behavior were apparent in the first interview. Missions and tasks of alter personalities were screened in this interview. Four of them were frightening and they were leading to inappropriate behavior. Three alter personalities were of a rather hopeful and benign type representing joy and happiness. The frightening ones were of a problem-solving type. The therapist told her that she was lamenting about her life uninterruptedly and all her days were full of distress. The patient accepted this. She admitted that she did not want to live continuosly lamenting.

The first fusions were conducted on frightening alter personalities. She experienced strength and having rules. "Her posture was more straight now", she said. Prior to this, she indeed had usually presented with a humpbacked posture indeed. Benign alters fused also in the same interview. The improvement of her mood was obvious i.e. she displayed loud laughters. Though she previously perceived herself to be quite fat, her perceptionof her body here became normal after fusions. She looked at the mirror and commented: "How thin I am ". She learned not to submit to her traumatic self. She realized that her daily life had been full of complaints during the last five years. When asked why she relinquished her control to the traumatic self, she said that she had no reason to, but had only become used to it. 
Previous therapists listened to her complaints for a long time which resulted in cherishing her traumatic self further. The new therapist declared that he will complete the treatment in six sessions, he underlined the presence of the trauma-self. She easily recognized her trauma-self which led her to utilize her problem-solving abilities.

The traumatic turning point has a special importance in psychotherapeutic work with the trauma-self. The traumatic turning point does not refer to the first trauma which the subject has experienced, remembers, or realizes in time, but rather to the most upsetting experience which happened most likely in childhood. ${ }^{16}$ The most upsetting traumatic experience takes a major role in the development of trauma schemata. ${ }^{44}$ Insisting on working on trauma in context of the trauma-self maintains and increases the psychopathology. Successful processing of the experience related to traumatic turning point makes other traumatic experiences easier to approach and to solve. The most important trauma should be identified in collaboration with the patient. This depends on qualitative impact of the stressor on the individual rather than its magnitude..$^{45}$

\section{Case example:}

A 35-year-old female patient was divorced and living with an other man as a mistress. She had received psychotherapy for ten years and had multiple hospitalizations when the tretament was taken over by a new therapist E.Ö.. She had more than 20 alter personalities with including those with child and "prostitute" identities. She experienced dissociative psychosis episodes several times and had conversion symptoms transiently. She had fears of "going crazy" and believed that "nothing would change". She wanted to be "emotion-less", she believed that she could not "bear to a normal life".

Between the ages of $2-8$ she grew up in an orphanage due to the extreme poverty of her parents. Subsequently, she alternated living with her mother and relatives until she married at age 19. She converted to Christianity her husband's religion, but returned to Islam after her divorce and while living with a married man belonging to a fundamentalist Islamic confession. She wore headscarf for a period but later abandoned it.

She had been molested sexually by her cousins throughout 8 and 18years of age. She did not attach much importance to these experiences. She complained and talked about her death wishes. Following recognition of the trauma-self, she remembered a further traumatic experience. Her father had molested her sexually throughout 8 and 18years of age. Her response to this recognition made it obvious that this was the main trauma in her history. She realized following this disclosure that the trauma-self had emerged after this traumatic turning point.

The patient was informed for the first time that her father had a schizophrenic disorder. This helped her to forgive him. Being unaware of this traumatic turning point, the patient had not been able to process her other traumatic experiences. The treatment led to integration after 7 months i.e. 22 interviews. The patient has had no relapse for 7 years. She has had a happy marriage for two years now.

Least but not last, we hypothesize that the patients' position as both a subject and an object of psychotherapy is closely related to the concept of resistance. In our view, the extent of patient participation in psychotherapy i.e. therapeutic mutuality is correlated inversely with resistance. By the same token, the qualities and skills of the therapist working with the trauma-self are also important for a better outcome. ${ }^{46,47,48}$ Many contemporary clinicians agree that treatmentresistance may also have its origins at the therapist's part of the process ${ }^{48}$ thus, Strean ${ }^{5}$ talks about "counterresistance." Considering resistance as a structural phenomenon inherent in the analytical process which can never be overcome totally which can only be minimized and should, at least, not exacerbated, Lacan ${ }^{49}$ stated even: "there is no resistance on the part of the subject" and further "there is no other resistance to analysis than of the analyst himself". ${ }^{50}$ Thus, we believe that further research endeavors on psychotherapy of trauma and stress- related and dissociative disorders ${ }^{51}$ should not only focus on patient characteristics but on therapist characteristics as well.

\section{Acknowledgements}

The authors wish to thank Semra Kecelioglu, CSW who copyedited the original manuscript into reader-friendly standard English, while preserving its original intent and content.

\section{Conflicts of interest}

Author declares there are no conflicts of interest.

\section{Funding}

None.

\section{References}

1. Freud S. Studien über Hysterie (Studies on hysteria). Fischer Taschenbuch Verlag, UK. 1895/1974.

2. Freud S. The interpretations of dreams. Australia. 1900. p. 517.

3. Kalsched D. The inner world of trauma: Archetypal defences of the personal spirit. Routledge, UK. 1996

4. Bromberg PM. Standing in the spaces. Essays on clinical process trauma \& Dissociation. Analytic Press, USA. 1998. p.1-22.

5. Strean HS. Resolving counter-resistances in psychotherapy. Brunner Mazel, USA. 1993. p.1-258.

6. Moone BE, Fine BD. Psychoanalytic terms and concepts. Yale University Press, USA. 1990. p.1-210.

7. Kluft RP. Treatment of multiple personality disorder: a study of 33 cases. Psychiat Clin North Am. 1884;7(1):9-29.

8. Ellason JW, Ross CA. Two year follow-up of inpatients with dissociative identity disorder. Am J Psychiatry. 1997;154(6):832-839.

9. Chu J. Rebuilding shattered lives. The responsible treatment of complex post-traumatic and dissociative disorders. Wiley. 1998.

10. Kluft RP. The difficult-to-treat patient with dissociative disorder. In: MJ Dewan \& RW Pies (Eds.), The difficult-to-treat psychiatric patient, American Psychiatric Publishing, USA. 2001. p.209-242.

11. Şar V, Öztürk E. Functional dissociation of the self: a sociocognitive approach to trauma and dissociation. $J$ Trauma Dissociation. 2007;8(4):69-89.

12. Brewin CR. Post-traumatic stress disorder. Malady or myth? New Haven, Yale University Press. 2005.

13. Sadler JZ. The psychiatric significance of the personal self. Psychiatry. 2007;70(2):113-129.

14. Goffman E. The presentation of self in everyday life. Doubleday Anchor Books, USA. 1959. p.1-173.

15. Metzinger T. Being no one. The self-model theory of subjectivity. MIT Press, USA. 2003. p.1-714.

16. Sar V, Öztürk E. What is trauma and dissociation? J Trauma Practice. 2005;4(1-2):7-20. 
17. Howell EF. Narcissism, a relational aspect of dissociation. J Trauma Dissociation. 2003;4(3):51-71.

18. Chefetz RA. Affect dysregulation as a way of life. J Am Acad Psychoanalysis. 2000;28(2):289-303.

19. Koenen KC. Developmental epidemiology of PTSD. Self-regulation as a central mechanism. Ann NY Acad Sci. 2006;1071:255-266.

20. Battegay R. Narzissmus und Objektbeziehungen. Über das Selbst zum Objekt (Narcissism and object relations: from self to object). Hans Huber Verlag, UK. 1979. p.1-256.

21. Frewen PA, Pain C, Dozois DJA, et al. Alexithymia in PTSD. Psychometric and fMRI studies. Ann NY Acad Sci. 2006;1071:397-400.

22. Van der Hart O, Nijenhuis ERS, Steele K. The haunted self. Structured dissociation and the treatment of chronic traumatization. Norton, USA. 2006. p.1-3.

23. Şar V. Dissociative depression: a common cause of treatment resistance. In: Renner W (Ed.), Female Turkish migrants with recurrent depression, Studia, Australia. 2011. p.112-124.

24. Sar V. Dissociative depression is resistant to treatment-as-usual. $J$ Psychol Clin Psychiatry. 2015;3(2):00128.

25. Şar V, Akyüz G, Öztürk E, et al. Dissociative depression among women in the community. J Trauma Dissociation. 2013;14(4):423-438.

26. Şar V. The many faces of dissociation: Opportunities for innovative research in psychiatry. Clin Psychopharm Neurosci. 2014;12(3):171-179.

27. Van der Hart O, Steele K. Time distortions in dissociative identity disorder. Dissociation. 1997;10(2):91-103.

28. Freud S. Trauer und Melancholie (Mourning and melancholia). In: Psychologie des Unbewussten (The psychology of unconscious). Study Edition, Vol.III. Frankfurt am Main: S.Fischer Verlag. 1900. p.193-212.

29. Blizard RA. Disorganized attachment, development of dissociative self-states, and a relational approach to treatment. J Trauma \& Dissoc. 2003;4(3):27-50.

30. Steele K, Van der Hart O, Nijenhuis ERS. Phase-oriented treatment of structural dissociation in complex traumatization:overcoming traumarelated phobias. J Trauma Dissociation. 2005;6(3):11-53.

31. Şar V, Alioğlu F, Akyüz G. Depersonalization and derealization in selfreport and clinical interview: the spectrum of borderline personality disorder, dissociative disorders, and healthy controls. J Trauma Dissociation. 2016;17:1-17.

32. Şar V, Koyuncu A, Öztürk E, et al. Dissociative disorders in the emergency psychiatric ward. Gen Hosp Psychiatry. 2007;29(1):45-50.

33. Şar V, Akyüz G, Kundakçi T, et al. Childhood trauma, dissociation, and psychiatric comorbidity in patients with conversion disorder. Am J Psychiatry. 2004;161(12):2271-2276.
34. Şar V,Akyüz G, Dogan O, et al. The prevalence of conversion symptoms in women from a general Turkish population. Psychosomatics. 2009;50(1):50-58.

35. Taycan O, Şar V, Çelik C, et al. Trauma-related psychiatric comorbidity of somatization disorder among women in eastern Turkey. Compr Psychiatry. 2014;55(8):1827-1846.

36. Van der Hart O, Witztum E, Friedman B. From hysterical psychosis to reactive dissociative psychosis. J Traumatic Stress. 1993;6(1):43-64.

37. Şar V, Öztürk E. Psychotic presentations of dissociative identity disorder In: P Dell \& JO’Neil (Eds.), Dissociation and dissociative disorders: DSM-V and beyond, Routledge Press, USA. 2009. p.535-545.

38. Tutkun H, Yargic L, Sar V. Dissociative identity disorder presenting as hysterical psychosis. Dissociation. 1996;9(4):241-249.

39. Şar V, Alioğlu F, Akyüz G, et al. Dissociative amnesia in dissociative disorders and borderline personality disorder: Self-rating assessment in a college population. J Trauma Dissociation. 2014;15(4):477-493.

40. Putnam FW. Diagnosis and treatment of multiple personality disorder. Guilford, USA. 1989. p.1-351.

41. Krakauer SY. Treating dissociative identity disorder. The power of the collective heart. Philadelphia, Brunner Routledge. 2001.

42. Kluft RP. Treating the traumatic memories of patients with dissociative identity disorder. Am J Psychiatry. 1996;153(7 Suppl):103-110.

43. Chu JA, Dell PF, Van der Hart O, et al. International Society for the Study of Trauma and Dissociation guidelines for treating dissociative identity disorder in adults (3rd edn). J Trauma \& Dissoc. 2011;12:115-187.

44. Fischer G, Riedesser P. Lehrbuch der Psychotraumatologie. Ernst Reinhardt Verlag, UK. 1999. p.1-431.

45. Spitzer C, Abraham G, Reschke K, et al. Posttraumatic stress disorder following high- and low-magnitude stressors in psychotherapeutic inpatients. Clin Psychol Psychotherapy. 2000;7(5):379-384.

46. Wilson JP, Lindy JD. Countertransference in the treatment of PTSD. Guilford Press, USA. 1994. p.1-406.

47. Pearlman LA, Saakvitne KW. Trauma and the therapist Countertransference and vicarious traumatization in psychotherapy with incest survivors. New York, Norton. 1995.

48. Dalenberg CJ. Countertransference and the treatment of trauma American Psychological Association, USA. 2000. p.1-305.

49. Lacan J. The Seminar of Jacques Lacan: Book 2: The Ego in Freud's Theory and in the Technique of Psychoanalysis, 1954-55. Norton, USA. 1988. p.228.

50. Lacan J. Ecrits: a selection. Tavistock Publications, UK. 1978. p.1-235.

51. Şar V. Developmental trauma, complex PTSD and the current proposal of DSM-5. Eur J Psychotraumatology. 2011;2:5662. 